\title{
ARTIFICIAL INTELligenCE MODELS FOR CRIME Prediction in URBAN SpaCES
}

\author{
Ana Laura Lira Cortes ${ }^{1}$ and Carlos Fuentes Silva ${ }^{2}$ \\ ${ }^{1}$ EngineeringSchool, Universidad Autónoma de Querétaro, México \\ ${ }^{2}$ Educational Program of Engineering in Manufacturing Technologies, Universidad \\ Politécnica de Querétaro, México
}

\begin{abstract}
This work presents research based on evidence with neural networks for the development of predictive crime models, finding the data sets used are focused on historical crime data, crime classification, types of theft at different scales of space and time, counting crime and conflict points in urban areas. Among some results, $81 \%$ precision is observed in the prediction of the Neural Network algorithm and ranges in the prediction of crime occurrence at a space-time point between $75 \%$ and $90 \%$ using LSTM (Long-ShortSpace-Time). It is also observed in this review, that in the field of justice, systems based on intelligent technologies have been incorporated, to carry out activities such as legal advice, prediction and decisionmaking, national and international cooperation in the fight against crime, police and intelligence services, control systems with facial recognition, search and processing of legal information, predictive surveillance, the definition of criminal models under the criteria of criminal records, history of incidents in different regions of the city, location of the police force, established businesses, etc., that is, they make predictions in the urban context of public security and justice. Finally, the ethical considerations and principles related to predictive developments based on artificial intelligence are presented, which seek to guarantee aspects such as privacy, privacy and the impartiality of the algorithms, as well as avoid the processing of data under biases or distinctions. Therefore, it is concluded that the scenario for the development, research, and operation of predictive crime solutions with neural networks and artificial intelligence in urban contexts, is viable and necessary in Mexico, representing an innovative and effective alternative that contributes to the attention of insecurity, since according to the indices of intentional homicides, the crime rates of organized crime and violence with firearms, according to statistics from INEGI, the Global Peace Index and the Government of Mexico, remain in increase.
\end{abstract}

\section{KEYWORDS}

Artificial Intelligence, Neural Networks, Crime Prediction, Crime Prevention, Computer Vision

\section{INTRODUCTION}

Crime in Mexico has reached alarming figures, intentional homicides, violence with firearms, drug dealing, among others, do not diminish, despite the strategies and efforts of the government to combat crime. The figures published by organizations such as INEGI, the Global Peace Index, and the Government of Mexico itself, show that this problem has not been contained. This context is described in a general way in Section 2.

Due to the aforementioned problems, that also occur in other countries of the world,it is necessary to review models that, from technology, have contributed to the improvement of the operational intelligence of those responsible for guaranteeing the safety of cities, whether in police forces, in intelligence units or in urban space surveillance tasks. 
Therefore, several studies related to the application of neural networks algorithms in crime prediction are described in Section 3, such as Naive Bais Regression, Support Vector Machine, Random Forest, as well as Neural Network, Recurrent Neural Networks (RNN) and Long - Short - Term - Memory (LSTM), among others; the results show high rates of accuracy in predictability, with different data sets related to space and time and their correlation with crimes such as commercial, residential or pedestrian theft in cities like Atlanta and Baltimore in the United States. Likewise, this section describes the result of the tests with neural network models such as Feed-Forward Network, Recurrent Neural Network (RNN), Convolutional Neural Network $(\mathrm{CNN})$ under the same training methods and conditions affecting their performance with data from the cities of Chicago and Portland.

Besides, applications based on intelligent technologies that have been incorporated and currently operate in the field of justice or police intervention in different countries are exposedin Section 4, since each location has a different context not only in the criminal situation but in the urban, as well as in public security policies.

Finally, Section 5incorporates ethical considerations regarding the use of these predictive techniques imply a responsibility in judicial systems that take into account guarantees such as respect for human rights and non-discrimination, data quality and security, transparency in the processing techniques, and the user's right to be informed about the nature of the resolutions coming from AI algorithms. Mainly in Europe, there are works on the approach of principles that regulate these technologies in judicial systems, such as the European Commission for the Efficiency of Justice.

Derived from the review of the accuracy these technologies have, it is necessary to investigate and test them in several contexts, to generate local predictive models that contribute to crime prevention, either in institutional security and justice or from the perspective of citizen prevention who transits in public spaces, where the crime mostly affect.

\section{ConteXt of Crime in MeXico}

According to what is mentioned in Gobierno de México (2019-2024), regarding security, the National Institute of Statistics and Geography reports that in Mexico more than thirty-one thousand crimes are committed per year; about $99 \%$ of them go unpunished. Frequently the figure of 100 intentional homicides a day is reached.

Other information from the Global Peace Index (2020), reports that, in 2019, the level of peace in Mexico had a decline of $4.3 \%$, deteriorating for the fourth consecutive year. This was largely due to a $24.3 \%$ increase in the crime rate of organized crime. The level of peace in Mexico has deteriorated $27.2 \%$ in the last five years. This deterioration was mainly since the national homicide rate increased to $86 \%$, going from 15 deaths per 100,000 inhabitants in 2015 to 28 in 2019. Violence with firearms is also on the rise: at the national level, the crime rate committed with these weapons more than doubled, from 13.6 per 100,000 inhabitants in 2015 to 29.6 in 2019.Since 2015, the crime rate of organized crime has increased by more than $46 \%$. The greatest deterioration was observed in the drug dealing crime rate, which increased by $75 \%$. Also, at the national level, homicide is currently the leading cause of death among young people. Each year, more than a third of homicide victims are between the ages of 15 and 29.

The National Public Security Strategy of the Federal Government (2019-2024), mentions that the dimension of the problem cannot be reduced to the phenomenon of drug trafficking, because it only represents one of the activities of organized crime and does not reveal the depth and extent 
Machine Learning and Applications: An International Journal (MLAIJ) Vol.8, No.1, March 2021

of the crime violence, which falls daily on people. All areas of social and economic life are being affected by crime. Beyond drug trafficking and organized crime, the life of the citizen is impacted by crimes of the common order. At home, in the neighborhood, when commuting to the workplace, at school, and while driving on the streets, Mexicans live in constant fear.

The context of violence that prevails, not only in Mexico but worldwide, leads different organizations to direct their efforts to the gathering and analysis of information about the opinion of the people in this regard, for example, in his study, Morquecho (2008), mentions that "at a global level, the United Nations Organization conducts the International Crime Victimization Survey". The questionnaire includes three aspects: the percentage of victimization, the characteristics of the ways of committing crimes, and the opinion on insecurity. The results show that people have a perception that insecurity in their cities is not only increasing but is being carried out with more violence.

The complex problem of insecurity practically all over the world, determined by the occurrence of different types of crime in specific places of urban space, generates high levels of fear and concern in people, repeatedly impacting their patterns of social behavior, mental health, and transformation of the space with the use of protection mechanisms to through which, they seek to feel more safety.

According to Alparslan et al (2020), there is a very strong impulse towards the development of models to obtain statistics on crime prediction, to check why it happens, when it would happen, and to whom it would happen. And although there are different models, algorithms, and reasons why the topic of crime prediction is addressed, the common denominator is that in many cities around the world the prevalence of crime affects citizens in urban environments, therefore, it is trying to take advantage of the development of artificial intelligence to provide solutions that help address this problem.

\section{Methodological Approaches for Crime Prediction with NEURAL NETWORKS}

Several authors have studied the occurrence of crime by applying deep learning, developing predictive models to analyze and generate information for crime prevention, which help in police intelligence activities, mapping the most conflictive areas in the city, risk prevention in the event of certain crimes, and police intervention in the face of illegal alerts in the city.

Scientific work has been carried out around crime prediction through neural networks using different variables according to the specific context, for example, in their work, Hicham et al (2018), propose a crime prediction model based on prepared historical data and transformed into space-time data by crime type, to be used in machine learning algorithms and then predict, with the maximum precision, the risk of having crimes in a space-time point in the city.

The model shown in Figure 1, proposes several layers with two types of data: HISTORICAL CRIME DATA (HIST DATA) and SITE INFORMATION (LOC DATA).In the experimentation and training phase, machine learning algorithms were used, such as Regression, Naive Bais, Support Vector Machine (SVM), Decision Tree, and Random Forest. Likewise, tests were carried out with algorithms such as Neural Network, Recurrent Neural Networks (RNN), and LongShort-Term-Memory (LSTM) to find the algorithm that gave good results in terms of precision and response time. 
It was found that some algorithms do not work with the data format such as Naive Bais and SVM. The Random Forest algorithm takes a long time for a single iteration and yields 59\% accuracy. The Decision Tree generates a 38\% accuracy in the second iteration and remains stable. The Neural Network algorithm is better suited to test data and is faster in response times generating $81 \%$ accuracy.

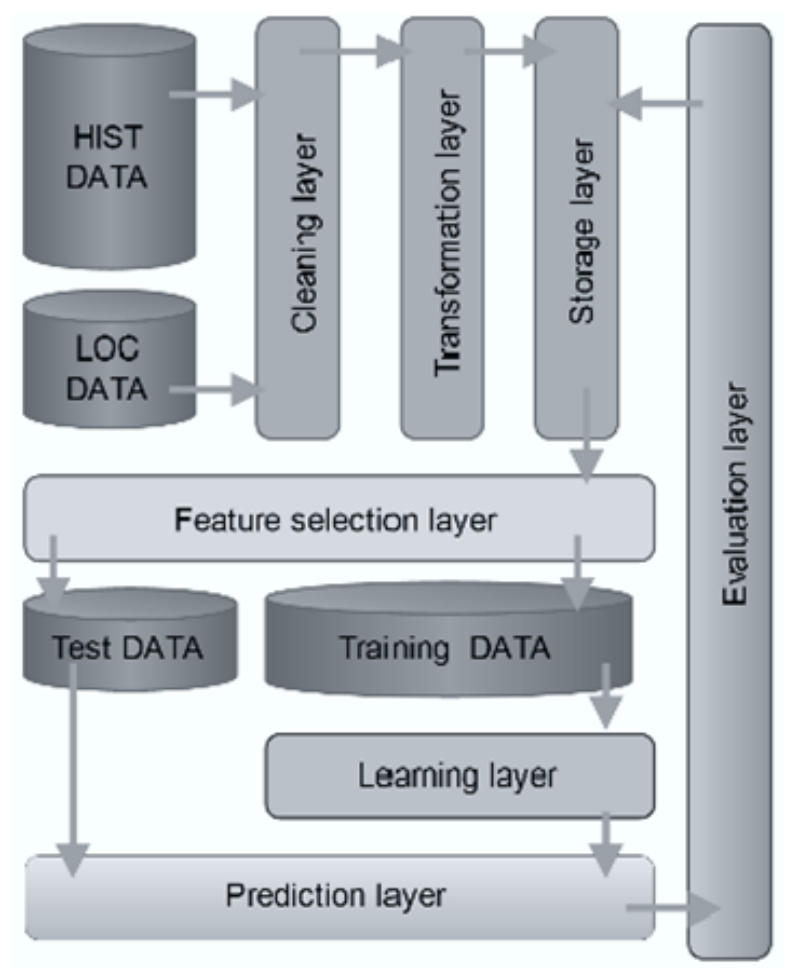

Figure 1. Predictive Model, Hicham et al (2018)

In the study carried out by Yuting and Li (2019), the predictability of three types of theft is compared, using LSTM (Long-Short-Space-Time), a variant of Recurrent Neural Networks (RNN), to understand the correlation of three types of theft with different characteristics so its predictability varies on different spatial and temporal scales. Commercial, pedestrian, and houseto-room thefts are compared in Atlanta and Baltimore, USA. The results show that the predictability between these differs in cities, for example, in Atlanta commercial theft is more predictable than residential and pedestrian, with a correlation coefficient around 0.75 . While in Baltimore, residential and commercial robbery reaches an approximate predictability coefficient of 0.90 , much higher than pedestrian robbery.

On the other hand, the work carried out by Stec (2018), aims to take advantage of neural networks to make crime prediction of the "next day" in specific areas of the cities of Chicago and Portland. As they show in Table 1, they worked on four models of neural networks, such as FeedForward Network, Recurrent Neural Network (CNN), Convolutional Neural Network (CNN), and Recurrent Convolutional Network $(\mathrm{RCN})$ that process different sets of spatial and temporal data to establish the relationship between these and crime, identifying the network that yields the best levels of precision in each prediction task, the precision of the results generated by each type of network is validated by varying the data sets under the same training methods and finally, the conditions that affect the performance of the model are explored. 
Machine Learning and Applications: An International Journal (MLAIJ) Vol.8, No.1, March 2021

Table 1. Accuracy of classification results byStec (2018)

\begin{tabular}{|l|c|c|c|c|c|}
\hline & Chicago Total & Chicago Type 1 & Chicago Type 2 & Chicago Type 3 & Portland Total \\
\hline Feed Forward & 71.3 & 64.3 & 61.0 & 56.5 & 62.2 \\
\hline CNN & 72.7 & 65.1 & 62.7 & 56.9 & 62.9 \\
\hline RNN & 74.1 & 65.5 & 63.6 & 57.6 & 63.8 \\
\hline RNN + CNN & $\mathbf{7 5 . 6}$ & $\mathbf{6 5 . 9}$ & $\mathbf{6 4 . 7}$ & $\mathbf{5 7 . 9}$ & $\mathbf{6 5 . 3}$ \\
\hline
\end{tabular}

Alparslan et al (2020), mention that one of the most used techniques is the search for the density of critical points on a map, using areas of higher crime incidence as indicators of future conflict zones since crime depends on various factors on multidimensional layers, which has been widely accepted as an indicator of future crime. The approach of these authors for their proposed models on crime prediction does not depend on the city, but rather poses crime as a regression, that is, a model that requires counting the crime in each area of the map, as well as adding these counts at different periods to predict the crime that would be expected to occur in that area, as shown in Figure 2. One difficulty with this approach is that researchers have to find a way to divide the city into a grid of cells, which can be a problem since not all large cities are a square, or have a compatible figure to be treated as a rectangle or square.

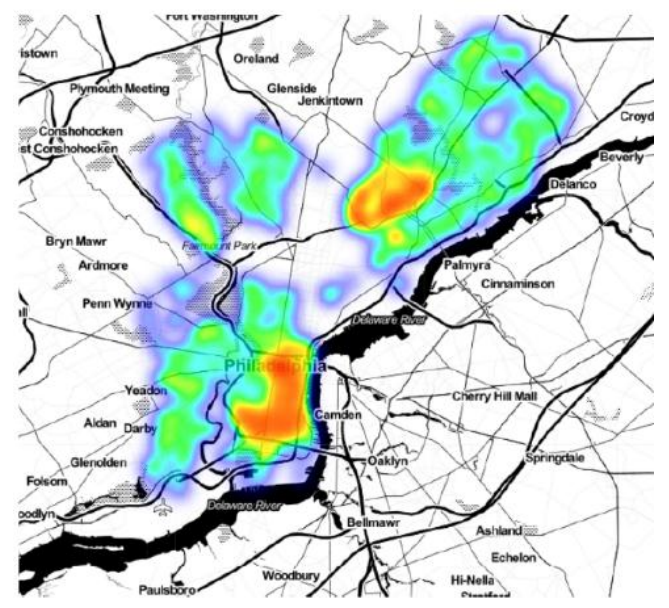

Figure 2. Crime mapping points per year on a map of Philadelphia byAlparslan et al (2020)

The approach proposed by the authors is to create groups (clusters) with the data and use it to count crimes instead of using cell grids to make a map. They worked with supervised and unsupervised learning models.

Among the results that were observed, as shown in Figure 3, there are some patterns related to the hours of highest crime incidence in the city, for example, the time of day with the least crimes is at 6 am when the criminals are asleep, and the critical hours are between 8 a.m. and 1 a.m., as well as lunch hours. When the scope of the time is changed from hours to months, as shown in Figure 4, a decrease in crimes is observed during the coldest months, compared to the spring and summer months, when the number of crimes such as robbery and prostitution increases. 


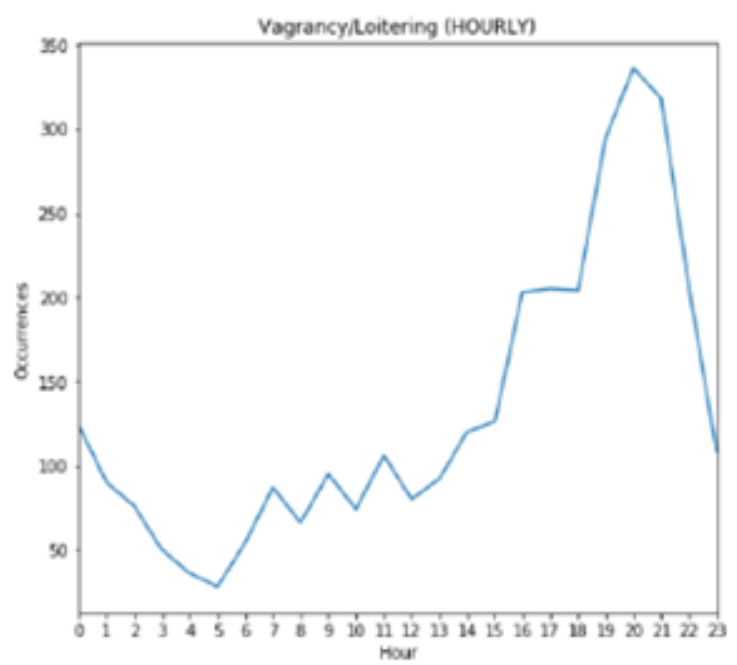

Figure 3. The hours of highest crime

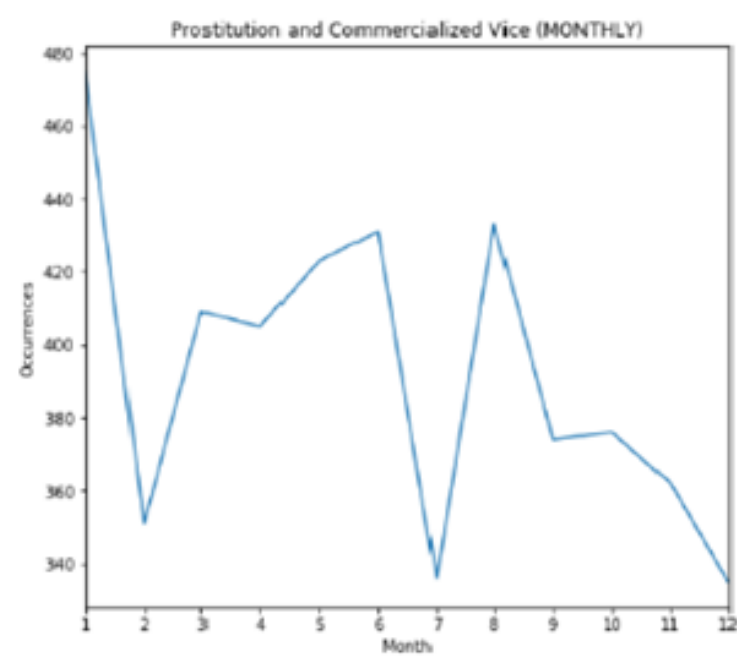

Figure 4. The months of highest crime

When working the network with the time value of years, it is observed that it is more difficult to see the significant trends. However, they observed that certain types of crimes have occurred less in recent years, such as vandalism, and others that have increased, such as theft.Finally, in this study, unsupervised learning techniques such as the K-Means clustering algorithm were combined to find the optimal number of clusters, and supervised learning methods using a sample of around 1.3 million records for training and testing. A summary of the four approaches is shown in the Table 2.

Another approach that also addressed crime prediction is the one carried out by Bogomolov et al (2014), in which, a 70\% accuracy was obtained to predict crime hotspots from human behavioral data derived from mobile network activity, in combination with demographic information, specifically, whether a given geographical area of a large European metropolis will have high or low crime levels in the next month.

The study of Ying-Lung (2018), applies machine learning for grid-based crime prediction. This study incorporates the concept of a criminal environment in grid-based crime prediction modeling, and establishes a range of spatial-temporal features based on 84 types of geographic information byapplying the Google Places API to theft data for Taoyuan City, Taiwan. Other algorithms applied in Kim (2019) for crime prediction, were K-Nearest-Neighbour with $39 \%$ accuracy and Boosted Decision Tree with $44 \%$ accuracy processing Vancouver crime data for the last 15 years. 
Machine Learning and Applications: An International Journal (MLAIJ) Vol.8, No.1, March 2021

Table 2. Some models used for the prediction

\begin{tabular}{|c|c|c|c|}
\hline Author & Modelsusedforprediction & Data Set & Crime \\
\hline $\begin{array}{l}\text { Bogomolov et al } \\
(2014)\end{array}$ & $\begin{array}{l}\text { 1.Random forest }-70 \% \\
\text { accuracy }\end{array}$ & $\begin{array}{l}\text { Mobile network } \\
\text { activity, demographic } \\
\text { information }\end{array}$ & Crime hotspot \\
\hline $\begin{array}{l}\text { Hicham et al } \\
(2018)\end{array}$ & $\begin{array}{l}\text { 1. Naive Bais } \\
\text { 2. Decision tree - } 38 \% \\
\text { accuracy } \\
\text { 3. Random forest }-59 \% \\
\text { accuracy } \\
\text { 4. Neural Network }-81 \% \\
\text { accuracy } \\
\text { 5. SVM }\end{array}$ & $\begin{array}{l}\text { Space-Time data by } \\
\text { crime type based on } \\
\text { historical crime data. }\end{array}$ & $\begin{array}{l}\text { Theft, battery, } \\
\text { criminal damage, } \\
\text { narcotics, assault, } \\
\text { other offence, etc. }\end{array}$ \\
\hline $\begin{array}{l}\text { Stec } \\
(2018)\end{array}$ & $\begin{array}{l}\text { 1. Feed Forward Network } \\
\text { 2. Recurrent Neural Network } \\
\text { 3. Convolutional Neural } \\
\text { Network } \\
\text { 4.Recurrent Convolutional } \\
\text { Network } \\
\text { * For accuracy see Table } 1\end{array}$ & Space -Time scale & $\begin{array}{l}\text { Violent crimes (e.g. } \\
\text { assault), theft crimes } \\
\text { and narcotic crimes. }\end{array}$ \\
\hline \multirow[t]{2}{*}{$\begin{array}{l}\text { Ying-Lung } \\
(2018) \text {, }\end{array}$} & $\begin{array}{l}\text { 1.Random Decision Forest. } \\
\text { 2.Support Vector Machine } \\
\text { 3.K-Near Neighbor }\end{array}$ & $\begin{array}{l}84 \text { types of } \\
\text { geographic } \\
\text { information. }\end{array}$ & $\begin{array}{l}\text { Grid based research } \\
\text { Hotspots }\end{array}$ \\
\hline & & $\begin{array}{l}\text { Time and spatial } \\
\text { factors }\end{array}$ & \\
\hline $\begin{array}{l}\text { Yutingand Li } \\
\text { (2019) }\end{array}$ & $\begin{array}{l}\text { Long-Short-Space-Time } \\
\text { (LSTM) - 75\%-90\% } \\
\text { accuracy }\end{array}$ & Space -Time scale & $\begin{array}{l}\text { Commercial, } \\
\text { pedestrian, and } \\
\text { house-to-room thefts. }\end{array}$ \\
\hline Kim et al (2019) & $\begin{array}{l}\text { K-Nearest-Neighbour - } 39 \% \\
\text { accuracy } \\
\text { Boosted Decision Tree }-44 \% \\
\text { accuracy }\end{array}$ & Space - Time scale & $\begin{array}{l}\text { Theft from vehicle, } \\
\text { mischief, offence } \\
\text { against a person. }\end{array}$ \\
\hline $\begin{array}{l}\text { Alparsan et al } \\
(\mathbf{2 0 2 0})\end{array}$ & $\begin{array}{l}\text { 1. K - Nearest Neighbors } \\
\text { 2. Naïve Bayesian Inference } \\
\text { 3. Decision Tree } \\
\text { 4. Random Forest } \\
\text { 5. Logistic Regression } \\
\text { 6. Support Vector Machine } \\
\text { 7. Multi-Layer Perceptron }\end{array}$ & $\begin{array}{l}\text { Clusters with the } \\
\text { highest crime } \\
\text { incidence in different } \\
\text { periods of time }\end{array}$ & $\begin{array}{l}\text { All other offenses, } \\
\text { assaults, thefts, } \\
\text { vandalism-criminal } \\
\text { mischief, theft fron } \\
\text { vehicle, narcotic - } \\
\text { drug law violations, } \\
\text { fraud, etc. }\end{array}$ \\
\hline
\end{tabular}

\section{ARtificial INTELLIGENCE IN THE FieLd OF JUSTICE}

In the field of justice, there are predictive software solutions based on AI, which for a long time already operates in different countries with favorable results and which are a sign of the paradigm shift in the prevention and intervention in the crime problem by regulatory bodies of public safety in cities. 
Machine Learning and Applications: An International Journal (MLAIJ) Vol.8, No.1, March 2021

For example, in Gallar (2020) it is mentioned that the director of the CRÍMINA Center of the Miguel Hernández University (UMH), Spain, investigates how artificial intelligence must be created that is applied in the field of security. ModeRad is a tool to reduce the number of Twitter messages that the police have to read before deciding whether or not to do a legal investigation. However, it is the human who analyzes the possible threat and makes the decisions. AI is limited to significantly reducing the sample, assuming something basic: that crime on the internet, as in the physical world, follows patterns.

The incorporation of expert systems, algorithms, and computational models for legal advice, prediction, and decision making is now a reality. The use of Legal Advisory Systems or legal advice systems; or Legal Decision Support Systems, have been incorporating a kind of artificial intelligence applied to the legal world.

In his work, Barona (2019) indicates that national and international cooperation in the fight against crime has experienced exponential effectiveness due to the development of technologies, which allow this collaboration in real-time, and not only between judicial bodies, but also reaches the police and intelligence services, who see in technologies much more agile and effective means in the prosecution of singular events, criminal organizations and, also, in the prevention of criminal behavior. Likewise, by way of example, it has been applied as control systems (through algorithms) that allow the detection of faces - facial recognition-, to identify people through the iris, fingerprint, movements, and a long etcetera, which they not only play to persecute crime, but they also entertain preventive control options that are aimed at maintaining security and social or collective order.

In his study on predictive algorithms at the service of justice, Belloso (2018), affirms that "among the functions of law security has always been present, the current citizen demands that the law be able to minimize uncertainty and danger, and, if possible, neutralize the risk". Artificial intelligence applications designed to improve legal research to make the search and processing of legal information faster and more efficient are already present in Judicial Offices and most law firms. Currently operating robot lawyers talk with humans and advise them in solving simple legal problems (DoNotPay and Lee \& Aly). Likewise, there are programs designed by companies that work to predict the outcome of court decisions using technological tools called predictive justice such as Watson / Ross from IBM and Blue J. Legal.

IALAB (2019) refers another application called PROMETEA that is the first predictive artificial intelligence at the service of justice in Argentina, it uses supervised machine learning and clustering techniques, based on manual and machine labeling. It operates as an expert system to automate document creation, perform intelligent searches, and assist in data control. It is currently used in the International Court of Human Rights, in the Constitutional Court of the Republic of Colombia and Prosecutors, specialized in Gender Violence and Autonomous City of Buenos Aires (CABA).

Also, in his study, Brennan (2017) mentions COMPAS, which stands for Correctional Offender Management Profiling for Alternative Sanctions, another software developed that works in sequential stages of criminal justice, including preventive and community corrections, probation, and prison. Its objectives include, but are not limited to, an accurate assessment of risk, public safety, institutional safety, equity, racial equity, and ease of use. Current developments involve advanced machine learning (ML) tools for risk prediction and theory-driven internal classification (IC) to address specific responsiveness among incarcerated prisoners. 
There are other predictive crime models such as the German one, in which Seidensticker (2018) defines "predictive surveillance" as a computer-assisted method to calculate the probability of crime in space. The goal is to identify risk areas where measurements are made for future policy actions. The Bavarian police have been the first to implement a predictive surveillance solution.

Since 2014, the PRECOBS (Pre - Crime Observation System) software developed by the Institute for Pattern-based Predictions (IfmPt), has been tested and used in the Bavarian Police in Munich, Middle Franconia, and Nuremberg. Using patterns of close repeats, the early warning system informs the police daily of crimes that could occur, particularly domestic robbery.

In the first instance, the criteria (trigger criteria) are defined to detect the repetition of crimes, for example, based on the modus operandi, the location, or the type of property. Secondly, the socalled "observation areas" are determined, where the occurrence of crimes has been close, and are the spatial reference for predictions. The criteria and the calculated areas are tested by the retrograde simulation to verify whether the chosen assumptions are valid. The prediction is displayed in 250x250m quadrants with different colors that symbolize the importance of the prediction as shown in Figure 5. Local police analysts are trained to evaluate predictions and initiate and review police measures.

According to Bertassi, (2018), XLAW was developed by Elia Lombardo, inspector of the Naples Police Station, and has been tested in that city and Prato. It arises under the idea that the crimes of theft and pickpockets are cyclical and permanent. Use machine learning to find crime models, use a large amount of data based on probabilistic estimates.

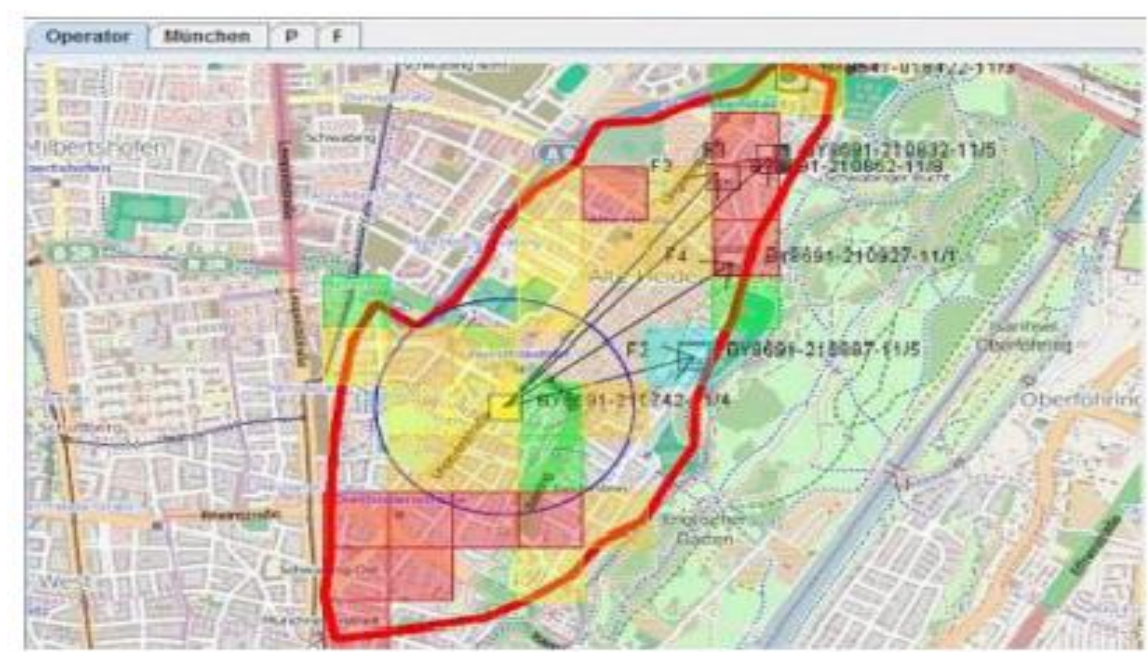

Figure 5. PRECOBS map by Predictive Policing in Germany

The most common criteria are a criminal record, a history of incidents in different regions of the city, the location of the police force, established businesses, and hours of operation, among others. From this, the software can indicate the highest probability of a crime occurring in a confidence interval.

Another software developed at the University of California called PredPol, which is mentioned in Ensign (2018), assumes regions that previously experienced crime, are susceptible to it happening again. This model uses data on incidence (including both reported and discovered) by region, to determine the actual crime rate does not use any demographic context or arrest profiles. PredPol predicts where crimes will be reported or discovered, not where they will happen. The 
police are sent every day to the areas with the greatest intensity in the prediction, and the incidents discovered their feedback into the system.

Belova, (2020), mentions VAAK, a Japanese initiative founded in 2017, has developed AI shoplifting detection software, which identifies potential shoplifters, using security camera footage to detect jitter, uneasiness, and other potentially suspicious body languages. The algorithm analyzes the images from the security camera and alerts about potential thieves through a smartphone application. See the summary in Table 3.

Table 3. Crime prediction software around the world

\begin{tabular}{llll}
\hline Autor & $\begin{array}{l}\text { Prediction } \\
\text { software }\end{array}$ & Country & \multicolumn{1}{c}{ Purpose } \\
\hline Gallar (2020) & ModeRad & Spain & $\begin{array}{l}\text { Monitor Twitter messages to decide whether } \\
\text { to initiate an investigation or not. }\end{array}$ \\
\hline IALAB (2019) & PROMETEA & Argentina & $\begin{array}{l}\text { Automate document creation, perform smart } \\
\text { searches, and assist in data control. }\end{array}$ \\
\hline Brennan (2017) & COMPAS & USA & $\begin{array}{l}\text { Risk prediction and an internal ranking of } \\
\text { prisoner response. }\end{array}$ \\
\hline Ceidensticker (2018) & PRECOBS & Germany & Calculate the probability of crimes in space. \\
\hline Bertassi, (2018) & XLAW & Italy & $\begin{array}{l}\text { Use machine learning to find crime models } \\
\text { with probabilistic estimates. }\end{array}$ \\
\hline Belova (2020) & VAAK & Japan & $\begin{array}{l}\text { Software to detect theft with AI. } \\
\text { Predict where crimes will be reported or } \\
\text { discovered. }\end{array}$ \\
\hline Ensign (2018) & PredPol & USA & \\
\hline
\end{tabular}

In Mexico City, according to Páez (2020), the Quadrant Program began, which divides the city into 5 zones, 15 regions, 74 sectors, and 865 quadrants to cover the territory by the SSPDF (Ministry of Public Security of the City of DF) to combat crime, have a closer relationship with citizens and generate more effective police action. However, the results of this study indicate that $63 \%$ of the people surveyed are not aware of the existence of technological tools for security.

\section{Ethical Considerations on the use of ARTificial InTElligence IN THE FIELD OF JUSTICE}

Miró (2020), refers that reducing human behavior to numbers is not easy, the problem of criminal behavior is multi-causality. AI is not designed to know the cause of things, but to estimate what is going to happen based on the deep knowledge of the relationships between what has happened. Work is being done to define the ethical keys of how these tools have to be used to take into account the guarantees of one's intimacy and privacy, that is, the ethics incorporated into the design. The European Union does have anethical will that, although it sometimes restricts excessively, contemplates the context of the technology that is being developed.

The European Commission for the Efficiency of Justice (CEPEJ) has adopted the first European text that establishes ethical principles regarding the use of artificial intelligence in judicial systems:European Ethical Charter on the Use of Artificial Intelligence in Judicial Systems and their environment. Among others:

- Respect for human rights and non-discrimination - The objective is to guarantee, from conception to practice, that the solutions guarantee respect for human rights and the privacy of personal data, avoiding that the applications do not reproduce or aggravate the discrimination and do not lead to deterministic analysis or practices. 
- Principle of quality and safety - It must be possible to process data by machine learning based on certified originals and the integrity of these must be guaranteed at all stages of processing.

- Principle of transparency - Accessibility and understanding of data processing techniques, as well as the possibility of audits by experts or external authorities.

- Principle "under user control" - Each user must be informed, in clear and understandable language, of the binding or non-binding nature of the solutions proposed by the AI instruments, the various options available and their right to advice legal and appeal to a court.

- Likewise, Belloso (2018) states that predictive justice - predictive justice systems or robot judges- works with the following principles:

- Prevention / precaution - At potential risk, caution. Prevention corresponds to the verified risk. AI systems could not be used in the following circumstances exist: i) the absence of algorithmic traceability; ii) the impossibility of a "kill button" or a secure AI containment mechanism; iii) when at any stage - design, development, or application - it is noticed that the system is based on distinctions that violate the principle of equality and nondiscrimination. Here this would operate as a kind of "algorithmic suspect category".

- Algorithmic self-determination - human self-determination must be guaranteed against the use of intelligent algorithms.

- Algorithmic transparency and the principle of impartiality of the validator - AI must be "transparent" in its decisions.

- Principle of algorithmic non-discrimination - Prevent AI from processing information or data under biases or distinctions.

\section{CONCLUSIONS}

Through the review and analysis of the research cited in this document, the efficacy of artificial intelligence algorithms and neural networks with supervised or unsupervised learning has been shown for the prediction of crime through investigations under specific urban contexts. Although there is surely now more research in this regard, this review represents a significant sample of the work that has been done on this topic, and by virtue of the fact that each city has its own particularities and security problems, it is necessary to continue applying these models in cities where violence and delinquency seem to have no end and where the justice system is fragile and inconsistent to meet this important citizen need: security.

The results of neural network tests have showna high level of accuracy in the prediction of urban space crime. Thus, it is essential to analyze and verify the usefulness of its application in the Mexican and Latin American context since there are no solutions, developments, or investigations aimed at predicting crime in our cities. And both to initiate a reflection on ethical considerations for the use of artificial intelligence algorithms for crime prediction in the Latin American context.

In the present review, we have observed that most of the data used for prediction were historical information about crime in the cities studied. Nevertheless, in future work, the prediction made 
Machine Learning and Applications: An International Journal (MLAIJ) Vol.8, No.1, March 2021

by machine learning algorithms could be complemented of the highest crime areas with the installation of surveillance equipment using real-time computer vision to identify, for instance, people, suspicious behavior patterns, weapons, cars and license plates that are approached by criminals when a robbery occurs. The above to identify and capture information about crime in real time within the area where the prediction was carried out. Further, there would be teams that can monitor 24 hours a day, without fatigue, without vacations and without corruption, strengthening crime prevention. In addition, the information in real time could be used to make more predictions, avoiding the bias that the historical information could have, testing the algorithms with characteristics of the environment, that is, with specific conditions that could increase the possibility for it to occur. a crime in the area, such as a poorly lit or low-traffic area, an area with vacant lots, a troubled area with gang fights, etc.

Considering the network infrastructure of the future in countries all around the world: Global System for Mobile Communications (GSMA), and taking advantage of a large amount of data, the transmission speed, and the connection stability of this network for citizens and organizations, it is necessary, as future work, to identify the development and use of applications for crime prediction with neural networks in GSMA urban spaces. This infrastructure is expected to be a reality in Mexico by 2025.

\section{REFERENCES}

[1] Alparslan, Y., et al (2020). Perfecting the Crime Machine. Documento disponible en: arXiv:2001.09764v1 [cs.CY] 14 Jan 2020

[2] Barona, S., (2019). Cuarta revolución industrial (4.0) o Ciberindustria en el proceso penal: revolución digital, inteligencia artificial y el camino hacia la robotización de la justicia*, Revista Jurídica Digital 3/1, 1-21 DOI: 10.24822/rjduandes.0301.1, 1-17.

[3] Belloso, N., (2018). Algoritmos predictivos al servicio de la justicia: ¿una nueva forma de minimizar el riesgo y la incertidumbre?, Revista da FaculdadeMineira de Direito V.22 N.43.

[4] Belova, Loudmila. (2020). Experience of Artificial Intelligence Implementation in Japan.https://www.researchgate.net/publication/340122096_Experience_of_Artificial_Intelligence_I mplementation_in_Japan.

[5] Bertassi, E., (2018). Considerations on Predictive Policing Software. Centro de Estudios Sociedade e Tecnología. Bulletin - Volume 3, Number 11, December 2018. Universidade de Sao Paolo.

[6] Bogomolov, A., et al (2014). Once upon a crime: towards crime prediction from demographics and mobile data. https://dl.acm.org/doi/10.1145/2663204.2663254

[7] Brennan, Tim \& Dieterich, William. (2017). Correctional Offender Management Profiles for Alternative Sanctions (COMPAS). 10.1002/9781119184256.ch3.

[8] Ensign, D., et al (2018). Runaway Feedback Loops in Predictive Policing. Proceedings of Machine Learning Research 81:1-12. Conference on Fairness, Accountability, and Transparency.

[9] Gallar, A., De Lara, A., (2020). “Conceptos y Contextos”, UMH Sapiens 26 | Inteligencia Artificial.

[10] Gobierno de México, (2019 - 2024). Estrategia Nacional de Seguridad Pública 2019 - 2024, Documento disponible en: https://infosen.senado.gob.m/sgsp/gaceta/64/1/2019-02-011/assets/documentos/Estrategia_Seguridad.pdf

[11] Hicham, A., et al (2018). A crime prediction model based on spatial and temporal data. Periodical of Engineering and Natural Sciences. Vol. 6, No.2, pp.360-364. Disponible en: http://pen.ius.edu.ba 
Machine Learning and Applications: An International Journal (MLAIJ) Vol.8, No.1, March 2021

[12] IALAB (2019). Laboratorio de Innovación e Inteligencia Artificial de la Universidad de Buenos Aires - Argentina. Disponible en: https://ialab.com.ar/prometea/

[13] Índice de Paz México 2020: Identificar y medir los factores que impulsan la paz, Sídney. Disponible en: indicedepazmexico.org.

[14] Kim S., Joshi P., Kalsi P.S. and Taheri P. (2019). Crime Analysis Through Machine Learning, doi: 10.1109/IEMCON.2018.8614828

[15] Miró, F. (2020). “Crimen y castigo en un algoritmo predictivo. Posibilidades tecnológicas y límites éticos de la IA". UMH Sapiens 26 | Inteligencia Artificial, Publishedon Feb 9, 2020.

[16] Morquecho, A., Vizcarra, L. (2008). Inseguridad pública y miedo al delito, un análisis de las principales perspectivas teóricas y metodológicas para su estudio. Recuperado de https://dialnet.unirioja.es/servlet/articulo?codigo $=2888467$

[17] Páez, C. A., Peón, I. E., \& Baracaldo, S. (2020). Programa de cuadrantes en Ciudad de México: diagnóstico según el modelo de sistema viable. Revista Científica General José María Córdova,18 (29), 27-58. http://dx.doi.org/10.21830/19006586.563

[18] Seidensticker, K., Bode, F., Stoffel, F., (2018). Predictive Policing in Germany. https://www.researchgate.net/publication/332170526

[19] Stec, A., Klabjan, D. (2018). Forecasting Crime with Deep Learning. Documento disponible en: https://arxiv.org/pdf/1806.01486.pdf

[20] YingLung. L., et al. (2017). Using machine learning to assist crime prevention, IEEE 6th Intl. Congr. on Advanced Appl. Inform. (IIAIAAI), Hamamatsu, Japan.

https://ieeexplore.ieee.org/document/8113405

[21] Yuting, M., Li, F., (2019). Predictability Comparison of Three Kinds of Robbery Crime Events Using LSTM. Association for Computing Machinery, ACM, ISBN 978+1-4503-7216-9. https://doi.org/10.1145/3354153.3354162

[22] Ying-Lung L., et al(2018). Grid-Based Crime Prediction Using Geographical Features. International Journal of Geo-Information.https://www.mdpi.com/2220-9964/7/8/298

\section{AUTHORS}

Ana Laura Lira Cortes is a student of the Ph.D. Innovation, Technology, and Habitat at the Faculty of Engineering of the Universidad Autónoma de Querétaro (UAQ), Mexico, she obtained her master's degree in Distributed Software Engineering in 2015. Her research interests include neural networks and citizen security.

Carlos Fuentes Silva received the degree of Process Control and Instrumentation Engineer from the Universidad Autónoma de Querétaro, Mexico in 2007; the degree of Master of Science (Instrumentation and Automatic Control) with a Specialty in Electronics from the UAQ in 2010; and the degree of Ph.D. Engineering from the UAQ in 2015. He is currently a Professor and Researcher at the Universidad Politécnica de Querétaro and a member of the National System of Researchers and the IEEE. His research areas are Intelligent Control (Neural Networks and Fuzzy Control), Digital Image Processing, Autonomous Navigation, and Artificial Intelligence.
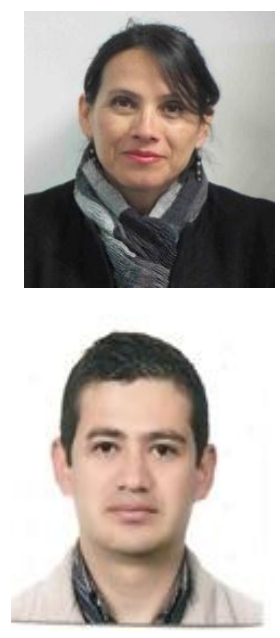